\begin{tabular}{|l|}
\hline Access this article online \\
\hline Quick Response Code: \\
\hline \\
Website: \\
www.Jlponline.org \\
\hline DOI: \\
10.4103/JLP.JLP_26_17 \\
\hline
\end{tabular}

Department of Pathology, Hamdard Institute of Medical Sciences and Research, New Delhi,

India

Address for correspondence:

Dr. Safia Rana,

Department of

Pathology, Hamdard Institute of Medical Sciences and Research, Jamia Hamdard,

New Delhi - 110 062, India.

E-mail: safia_rana2000@ yahoo.com

Submission: 07-02-2017

Accepted: 14-11-2017

\title{
Diagnostic challenges of tubercular lesions of breast
}

\author{
Zeeba Shamim Jairajpuri, Sujata Jetley, Safia Rana, Shaan Khetrapal, \\ Sabina Khan, Mohammad Jaseem Hassan
}

\section{Abstract:}

INTRODUCTION: Tuberculosis (TB) in the developing countries presents with both pulmonary and extrapulmonary manifestations. Breast TB, however, remains a rare presentation. Its importance lies in the fact that it may mimic malignancy or present as inflammatory lump/abscess.

AIMS AND OBJECTIVE: The aim of the present study is to highlight the importance of breast TB and its diagnostic challenges.

MATERIALS AND METHODS: It was a retrospective study conducted at a tertiary care hospital, over 2 years between 2013 and 2015 during which eight cases of breast lesions were diagnosed as of tubercular origin.

RESULTS: Granulomas were seen in five cases while three cases revealed only few epithelioid cells, and necrosis was seen in all cases on fine-needle aspiration cytology. Histopathological evaluation was available in six out of the eight cases, while acid-fast bacilli were positive in three cases, the characteristic granulomas were seen in all the six cases evaluated.

CONCLUSION: Significance of TB breast lies in the fact that it may masquerade as breast malignancy or pyogenic abscess. India is a developing country where TB is endemic, a high index of suspicion should be expressed in evaluating breast masses, and TB should be considered in the differential diagnosis.

Key words:

Abscess, breast lump, cytology, malignancy, tuberculosis

\section{Introduction}

Tndia is a developing country where Ituberculosis (TB) is endemic with both pulmonary and extrapulmonary manifestations of the disease. TB is caused by Mycobacterium tuberculosis and affects primarily the lungs. Extrapulmonary TB involving lymph nodes, intestine, and spine are also common. TB of breast is, however, extremely rare even in developing countries where pulmonary and other forms of extrapulmonary manifestations of TB are endemic. ${ }^{[1,2]}$ Breast is known to be resistant to $\mathrm{TB}$, similar to skeletal muscle and spleen. ${ }^{[3]}$ The clinical manifestations of breast TB are varied and may mimic carcinoma or pyogenic abscess hence often being a

This is an open access article distributed under the terms of the Creative Commons Attribution-NonCommercial-ShareAlike 3.0 License, which allows others to remix, tweak, and build upon the work non-commercially, as long as the author is credited and the new creations are licensed under the identical terms.

For reprints contact: reprints@medknow.com source of diagnostic dilemma. ${ }^{[4-6]}$ Moreover, confirmatory tests for $M$. tuberculosis such as Ziehl-Neelsen (ZN) staining or culture have low sensitivity, leading to difficulty in diagnosis and delayed treatment. ${ }^{[7]}$

Rarity of breast TB is evident with an incidence of $<0.1 \%$ of all breast lesions in Western countries and $3 \%-4 \%$ in TB endemic regions, such as India and Africa. ${ }^{[8]}$ Lactating multiparous women are more often found to be effected by the disease although males and elderly women are not spared. ${ }^{[9]} \mathrm{TB}$ of the breast, although considered to be a disease of the developing world, ${ }^{[10]}$ has shown a steady increase in the developed countries owing probably to migration of infected population from endemic zones and increasing number of

How to cite this article: Jairajpuri ZS, Jetley $S$, Rana S, Khetrapal S, Khan S, Hassan MJ. Diagnostic challenges of tubercular lesions of breast. J Lab Physicians 2018;10:179-84. 
immunocompromised patients. ${ }^{[1]}$ The aim of the present study is to highlight the importance of breast TB and its diagnostic challenges.

\section{Materials and Methods}

The present study was conducted in Hamdard Institute of Medical Sciences and Research and associated Hakeem Abdul Hameed Centenary Hospital, New Delhi, over 2 years between March 2013 and May 2015, and included eight cases of breast lesions diagnosed as TB. Patients were drawn from various outpatient department, majority cases presented with breast lump in Surgical and Gynecological Outpatients Department and were referred to cytopathology section of the Department of Pathology for evaluation. Patients were recruited according to the flow diagram [Figure 1].

Fine needle aspiration cytology (FNAC) of the lump was done and smears examined. The data on the age, sex, and the presenting clinical features of these cases were recorded along with cytopathological and histopathological findings whereever available. Routine hematological investigations with erythrocyte sedimentation rate were also correlated. Relevant detailed history of lump in the breast, nipple discharge, fever, weight loss, or cough were also elicited. Cytomorphological features contributing to the diagnosis included epithelioid cell granulomas, presence of epithelioid cells, suppuration, and necrosis. Histopathological evaluation was done on excised or debrided specimens. ZN Staining was done for acid-fast bacilli (AFB) to confirm the presence of bacilli on both cytological and histopathological samples whereever available. The Department of Pathology predominantly deals with extrapulmonary cases including lymph nodes, spine, nasal, muscle, breast, and intestinal cases. We received a total of 312 cases of extrapulmonary TB during the study period out of which eight cases were of breast TB.

\section{Results}

A total of eight cases out of the 312 cases of extrapulmonary TB were included in the study; all were females. The mean age of study group was $28 \pm 5.25$ years ranging 20-34 years of age. All lesions of the breast were unilateral in location in patients evaluated, the right breast and the left breast were affected equally, four patients each. Majority of the lesions were clinically localized to the periareolar region of the breast and had varied clinical presentation [Table 1 and Figure 2].

Lesions varied from firm nodule to erythematous areas with induration, similarly, clinical impression were of abscess, fibroadenoma, and malignancy in these cases. Fine-needle aspiration yielded smears which were evaluated for cytological findings are tabulated in Table 2.

Granulomas were seen in five cases while three cases revealed only few epithelioid cells [Figure 3]. Necrosis was seen in all cases, however, caseous type was present in only three cases while lesion was suppurative in four cases, clinically thought to be abscess and one case with a provisional clinical diagnosis of malignancy. Four cases yielded pus which was sent for culture and were found to be negative for AFB. Histopathological evaluation was available in six out of the eight cases, whereas AFB were positive in three cases [Figures 4 and 5]. The characteristic granulomas were seen in all the six cases evaluated. The standard antitubercular treatment was instituted in all the cases, however, two cases were lost to follow-up after initial period. All cases responded to treatment.

\section{Discussion}

TB has been recognized as an affliction with an enormous impact in terms of morbidity, mortality, and economic cost. ${ }^{[12]}$ India has the world's largest burden of TB, accounting for one-fourth (24\%) of the global TB incidence. ${ }^{[12]}$ Localization to the breast is not commonly seen even in developing countries like India where the disease is endemic. It was first described by Sir Astley Cooper in $1929 .{ }^{[13]}$ The importance of the TB breast lies in the fact that due to its infrequent occurrence and chances of a mistaken identity with other disease, it entails a high index of suspicion. Clinically, it is known to simulate many diseases of breast such as carcinoma, chronic granulomatous inflammation, chronic nonspecific inflammation, and duct ectasia. ${ }^{[14,15]}$

Tuberculous mastitis is usually unilateral, more commonly seen in women than in men. The higher risk in lactating women is attributed to, increase in blood supply to the breasts, dilated ducts and resultant increased chances of lacerations and infection. ${ }^{[9]}$ In the present study, all the patients were young women with the mean age of $28 \pm 5.25$, ranging from 20 to 34 years with unilateral lesions, $50 \%$ (4 cases) also gave history of lactation. The authors have reported cases ranging from age 6 months to 73 years, however, majority of them were between 20 and 40 years old. ${ }^{[16-18]}$ The lesions were localized equally to both sides in our cases similar to observations by Wilson and Macgregor ${ }^{[19]}$ however, in contrast others have reported right-sided lesion. ${ }^{[18]}$ No clinical significance could be assigned to lateralization of the lesions. Affliction of the breast by TB can be of two types, primary or secondary. Primary, when no demonstrable preexisting tubercular focus exists elsewhere in the body or it may be secondary to a lesion anywhere in the body. ${ }^{[20]}$ These preexisting lesions could be localized to a pulmonary focus or a lymph node in 
Table 1: Clinical profile of the patient

\begin{tabular}{|c|c|c|c|c|c|}
\hline \multirow[t]{2}{*}{ Case } & \multirow[t]{2}{*}{ Age (years)/sex } & \multicolumn{3}{|c|}{ Clinical presentation } & \multirow{2}{*}{$\begin{array}{l}\text { Clinical } \\
\text {-impression }\end{array}$} \\
\hline & & Side & Location & Type of lesion & \\
\hline 1 & 27/female & Left & Periareolar region & $\begin{array}{l}\text { Ulcerated lesion with surrounding edema with pus } \\
\text { discharge }\end{array}$ & Malignancy \\
\hline 2 & 28/female & Left & Subareolar region & Small firm nodule & Fibroadenoma \\
\hline 3 & 28/female & Right & Outer quadrant & Nodule with overlying skin edema and skin retraction & Malignancy \\
\hline 4 & $35 /$ female & Left & Periareolar region & Erythematous firm ill-defined indurated with scar & Abscess \\
\hline 5 & 20/female & Right & Outer and inner quadrant & Two firm swellings & Fibroadenoma \\
\hline 6 & 24/female & Right & Outer quadrant & Irregular firm to hard & Malignancy \\
\hline 7 & 34/female & Right & $\begin{array}{l}\text { Peri-areolar, extending into both } \\
\text { upper and lower outer }\end{array}$ & Erythematous, warm, tender, and indurated area & Abscess \\
\hline 8 & 28/female & Left & Periareolar region & Erythematous, warm, tender, and indurated area & Abscess \\
\hline
\end{tabular}

Table 2: Pathological profile of the patients

\begin{tabular}{|c|c|c|c|c|c|c|c|c|}
\hline \multirow[t]{2}{*}{ Case } & \multicolumn{5}{|c|}{ Cytological findings } & \multicolumn{3}{|c|}{ Histopathological findings } \\
\hline & Granuloma & Epitheliod cell & Necrosis & Neutrophils & AFB & Granuloma & Necrosis & AFB \\
\hline 1 & Few & Few & Caseous & - & + & Multiple & Caseous & + \\
\hline 2 & Numerous & Numerous & Caseous & - & - & Numerous & Caseous & - \\
\hline 3 & Not seen & Few & Suppurative & Present & - & Few & Suppurative & - \\
\hline 4 & Not seen & Few & Suppurative & Marked & + & Not available & & \\
\hline 5 & Few & Numerous & Caseous & Few & + & Numerous & Caseous & + \\
\hline 6 & Occasional & Few & Suppurative & Marked & - & Few & Suppurative & - \\
\hline 7 & Not seen & Few & Present & Numerous & - & Few & Caseous & + \\
\hline 8 & Few & Numerous & Suppuraive & Numerous & + & Not available & & \\
\hline
\end{tabular}

cervical, mediastinal, paratracheal, intestinal, mammary, or axillary region. Out of the eight cases in our series, six cases did not show any other focus of TB even on extensive workup while pulmonary lesions could be demonstrated in two patients. It has however been suggested by authors to exercise caution while making a diagnosis of primary TB as in most cases clinicians are unable to detect the true nidus of the disease. ${ }^{[21]}$

Clinical presentations of tubercular affliction of the breast are varied, ranging from round nodular lumps mainly in the upper outer quadrant of the breast. ${ }^{[8,22]}$ In more complex forms, it may present as indurated lesion often with sinus formation, associated with pain and discharge simulating an abscess while in others, involvement of the skin or the underlying muscle, nipple retraction creating the peau d'orange sign posing clinical problems in differentiation from breast carcinoma. ${ }^{[8,12,22-24]}$ The most common presentation is a lump in the breast, multiple lumps are however less frequent, one case in the our series presented with two swellings. The classical presentation of TB in breast is unfortunately less common, causing difficulty in clinical interpretation at times. ${ }^{[25]}$ None of the cases, in our study, were clinically suspected to be tubercular in origin, three cases mimicked features of malignancy, while two presented with nodules suspected to be fibroadenoma while the rest were mistaken for abscess.
The disease has been described to occur in three forms: nodular, diffuse, and sclerosing based on radiological and clinical characteristics. Nodular type is a slow-growing; oval tumor shadow on mammography difficult to differentiate from breast cancer. On the other hand, the disseminated form is characterized by multiple lesions, with sinus formation, mimicking inflammatory breast cancer on mammography. The sclerosing form is often seen in the elderly women with an exaggerated fibrotic process. ${ }^{[8,22,26]}$ Breast TB has also been classified by into five categories as follows ${ }^{[27,28]}$

a. Acute miliary type: Rare due to bloodborne infection in miliary TB

b. Nodular type: The most common type which presents as a localized lump with or without sinuses in one quadrant of the breast

c. Disseminated type: Involving the entire breast with multiple sinuses

d. Sclerosing type: Minimal caseation and extensive hyalinization of the stroma

e. Tuberculous mastitis obliterans: A rare form due to intraductal infection with fibrosis and obliteration of the ductal system.

In view of the varied clinical presentations and mimics of TB breast, diagnosing the disease is a challenge, the utility of imaging techniques such as mammography or ultrasonography is limited due to 


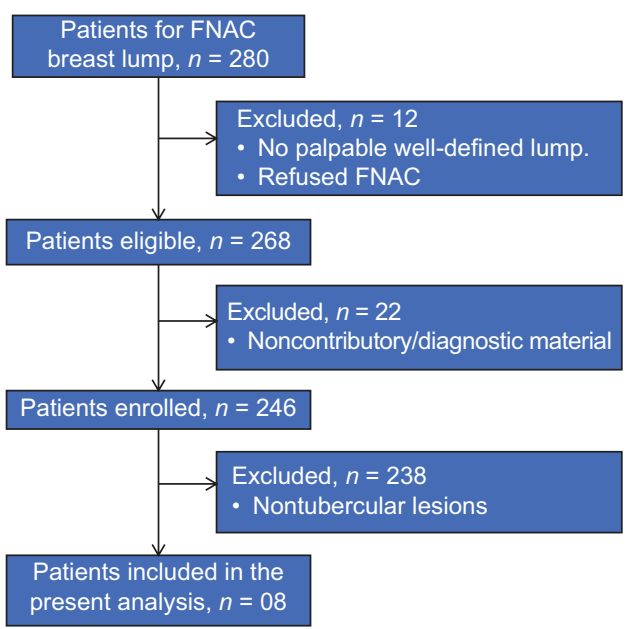

Figure 1: Flow diagram depicting recruitment of patients for the study

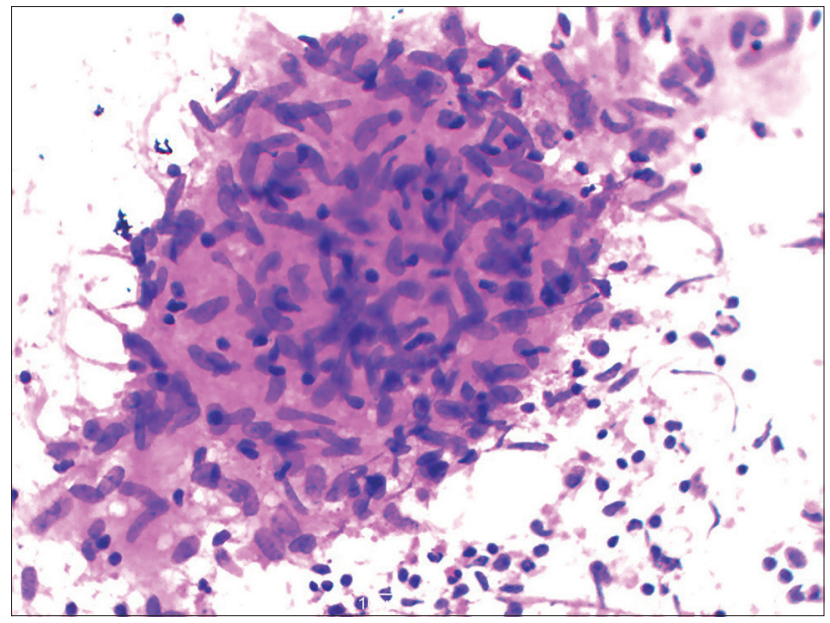

Figure 3: Microphotograph showing epithelioid cell granulomas from breast lump aspirate (Giemsa, $\times 40$ )

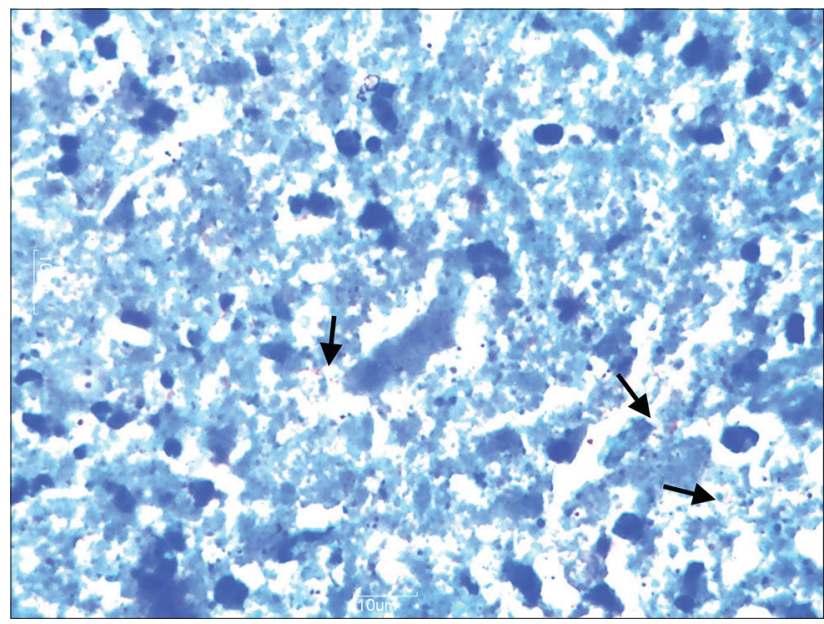

Figure 5: Microphotograph showing the presence of acid-fast bacilli (arrows) $(\mathrm{ZN}, \times 100)$

unreliability in distinguishing from carcinoma as well as variable pattern of presentation of TB, computed tomography and magnetic resonance imaging are not

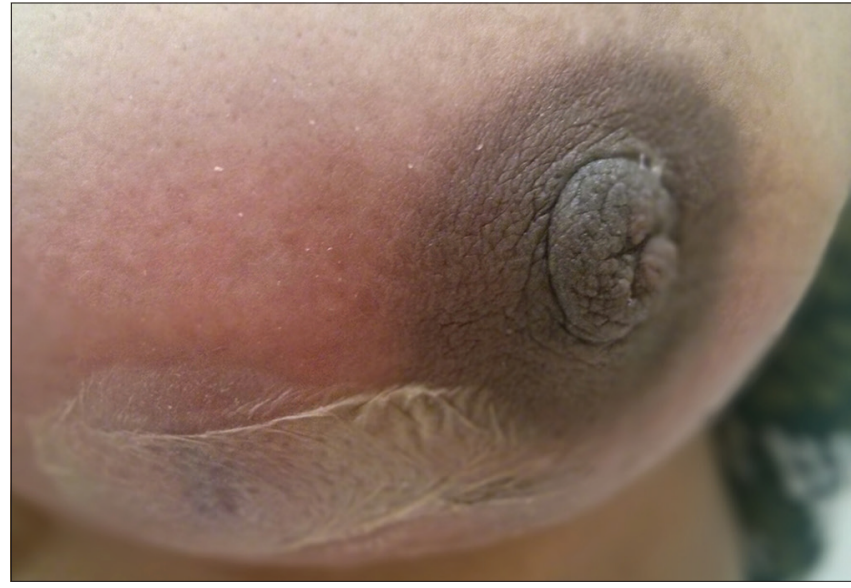

Figure 2: Clinical photograph showing manifestation of tuberculosis in breast in form of inflammed lump

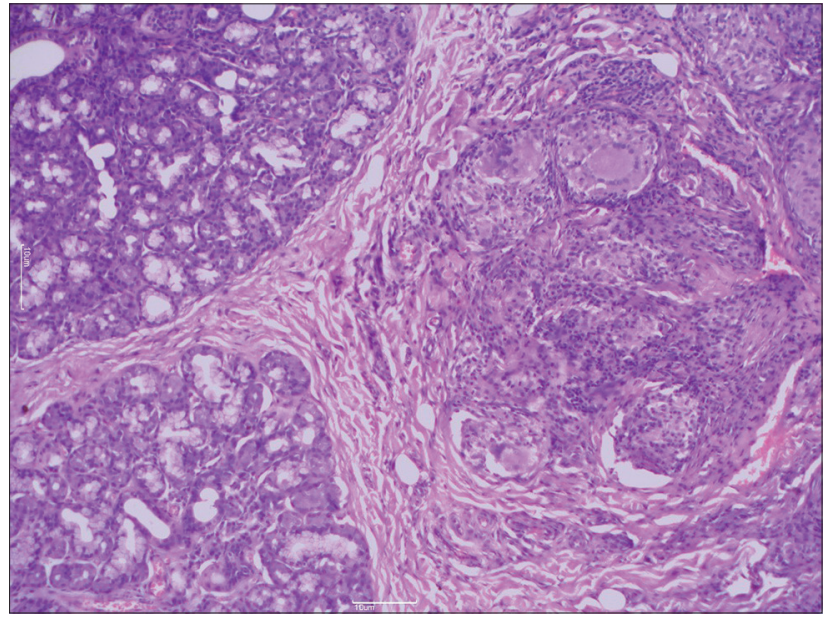

Figure 4: Microphotograph showing section of caseating epithelioid cell granulomas as well as adjacently lying normal breast tissue $(H$ and $E, \times 40)$

diagnostic without histological confirmation. ${ }^{[18]}$ More so, Mantoux test is also usually positive in endemic areas demonstrating only the previous exposure to TB. Hence, pathological evaluation plays a significant role in achieving a definite diagnosis, they are of more value than bacteriological examinations and are often preferred. ${ }^{[18]}$ Even though the gold standard for establishing breast TB is demonstration of $M$. tuberculosis by $\mathrm{ZN}$ staining or by culture, there are limitations. Histochemistry is often not practical and culture of $M$. tuberculosis is limited due to the delay in the final result along with the possibility of false-negative results in paucibacillary samples ${ }^{[8,18]}$ In the present study also, the cases were negative for AFB on culture. Polymerase chain reaction is a rapid and specific test but has low sensitivity, especially in AFB-negative smears. ${ }^{[8,29]}$ Although seldom used, molecular detection of $M$. tuberculosis is particularly useful in validation of diagnosis of TB in clinical settings where the diagnosis is uncertain. ${ }^{[2]}$ The present study is limited as the cases which were negative for 
AFB could not be validated by molecular methods.

FNAC of the breast lesion is recognized as an important, easily performed diagnostic tool for breast TB. ${ }^{[12]}$ In endemic countries like India, the finding of epithelioid cell granuloma and necrosis in FNAC smears warrants empirical treatment for TB even in the absence of positive $\mathrm{ZN}$ staining and culture for AFB. ${ }^{[8,27,30]}$ Characteristic epithelioid cell granulomas with necrosis were seen in all the cases in the present study with AFB positivity in only three cases. Utility of FNAC has been variable, it has been reported in literature, to diagnose approximately $73 \%$ of breast TB by some, ${ }^{[12]}$ and $43.3 \%$ by others. ${ }^{[27]}$ Literature review showed that on the basis of cytomorphology (epithelioid cell granulomas, necrosis, and AFB in cytology smears) alone a diagnosis of TB breast can be given confidently. ${ }^{[27,31,32]}$ Demonstration of AFB on FNAC is not mandatory; their numbers must be $10,000-100,000 / \mathrm{ml}$ of the material to be visualized microscopically. ${ }^{[24,27,31,32]}$ This fact explains, the often AFB negative smears of extrapulmonary sites which usually contain very few organisms. ${ }^{[18]}$

The most common cause of caseation in developing countries like India is TB. Detection of caseous material in cytology smears depends on experience of the pathologists. It is typically seen as acellular, granular material with loss of cellular details. ${ }^{[18,32,33]}$ Caseous necrosis was identified in three aspirates of the present case series. Epitheloid cell granulomas in a background of caseous necrosis, even in the absence of AFB is an indication of diagnosis of $\mathrm{TB}$, only after failure of sufficient trial of antituberculous treatment to give expected response, should an alternative diagnosis be suggested. ${ }^{[2]}$ Some authors have emphasized that even if well-formed epithelioid granulomas are absent, visualization of epithelioid histiocytes is the single most common indicator of granulomatous inflammation raising a strong suspicion of tuberculous etiology in endemic areas. ${ }^{[24]}$ Cases where an abscess-like picture is prominent due to acute inflammatory cells, epithelioid cells should be looked for carefully. ${ }^{[24]}$ FNAC is very useful, and it is a promising technique in the hands of experts.

A biopsy is, however, necessary for the confirmation of diagnosis. ${ }^{[25]}$ Detailed histological evaluation is also useful to rule out a coexisting carcinoma. Histopathological confirmation of TB of the breast is based on the evidence of epithelioid cell granulomas, Langhans giant cells with lymphohistocytic aggregates in caseous necrosis. Tubercular lesions of the breast need to be differentiated from other inflammatory granulomatous diseases, such as idiopathic granulomatous mastitis, sarcoidosis, Wegener's granulomatosis, and giant cell arteritis, fat necrosis along with infections like actinomycosis.
However, with appropriate ancillary investigations and characteristic morphological features, TB can be differentiated from these lesions. ${ }^{[18]}$ Histological examination of the tissue sample is considered to be one of the most reliable and definitive diagnostic tests.

\section{Conclusion}

Significance of TB breast lies in the fact that it may masquerade as breast malignancy or pyogenic abscess. In endemic countries like India, clinical history, cytomorphological features of epithelioid cell granulomas with or without necrosis, and AFB-negative FNAC smears a therapeutic trial of antitubercular drugs may be instituted histopathological evaluation though recommended for confirmation is not mandatory. We hope to generate awareness among physicians that a high index of suspicion should be expressed in evaluating breast masses and TB should be included in their differential diagnosis.

\section{Financial support and sponsorship Nil.}

\section{Conflicts of interest}

There are no conflicts of interest.

\section{References}

1. Nirhale DS, Athavale VS, Kishore K, Goenka GG. Is primary tuberculosis of breast a forgotten entity? Series of three cases. Med J DY Patil Univ 2014;7:62-4.

2. Bhosale AA, Joshi AR, Ashturkar AV, Pathak GS. Primary tuberculosis of breast: A case series. Ann Trop Med Public Health 2012;5:262-4.

3. Sharma PK, Babel AL, Yadav SS. Tuberculosis of breast (study of 7 cases). J Postgrad Med 1991;37:24-6, 26A.

4. Morino GF, Rizzardi G, Gobbi F, Baldan M. Breast tuberculosis mimicking other diseases. Trop Doct 2007;37:177-8.

5. Borens-Fefer B, Engohan-Aloghe C, Noël JC, Simon P, Bucella D, Boutemy $\mathrm{R}$, et al. Primary mammary tuberculosis presenting as a voluminous abscess. JBR-BTR 2008;91:54-7.

6. Fadaei-Araghi M, Geranpayeh L, Irani S, Matloob R, Kuraki S. Breast tuberculosis: Report of eight cases. Arch Iran Med 2008;11:463-5.

7. da Silva BB, Dos Santos LG, Costa PV, Pires CG, Borges AS. Primary tuberculosis of the breast mimicking carcinoma. Am J Trop Med Hyg 2005;73:975-6.

8. Marinopoulos S, Lourantou D, Gatzionis T, Dimitrakakis C, Papaspyrou I, Antsaklis A, et al. Breast tuberculosis: Diagnosis, management and treatment. Int J Surg Case Rep 2012;3:548-50.

9. Maroulis I, Spyropoulos C, Zolota V, Tzorakoleftherakis E. Mammary tubercu-losis mimicking breast cancer: A case report. J Med Case Rep 2008;2:34.

10. Zandrino F, Monetti F, Gandolfo N. Primary tuberculosis of the breast. A case report. Acta Radiol 2000;41:61-3.

11. Kervancioğlu S, Kervancioğlu R, Ozkur A, Sirikçi A. Primary tuberculosis of the breast. Diagn Interv Radiol 2005;11:210-2.

12. Jetley S, Jairajpuri ZS, Pujani M, Khan S. Exotic associations and presentations of an age old disease: Spectrum of tuberculosis in 
a developing country. Int J Res Med Sci 2016;4:2379-87.

13. Cooper A. Illustrations of the Diseases of the Breast: Part 1. London: Longman, Rees Orme, Brown and Green; 1829. p. 73.

14. Madhusudhan KS, Gamanagatti S. Primary breast tuberculosis masquerading as carcinoma. Singapore Med J 2008;49:e3-5.

15. Tuli R, O'Hara BJ,Hines J, Rosenberg AL. Idiopathic granulomatous mastitis masquerading as carcinoma of the breast: A case report and review of the literature. Int Semin Surg Oncol 2007;4:21.

16. Kedar GP, Bophate SK, Kherdekar M. Tuberculosis of breast. Indian J Tuberc 1985;32:146.

17. Elsiddig KE, Khalil EA, Elhag IA, Elsa ME, Suleiman GM, Elkhidir IM, et al. Granulomatous mammary disease: Ten years' experience with ne needle aspiration cytology. Int J Tuberc Lung Dis 2003;7:365.

18. Sen M, Gorpelioglu C, Bozer M. Isolated primary breast tuberculosis: Report of three cases and review of the literature. Clinics (Sao Paulo) 2009;64:607-10.

19. Wilson TS, Macgregor JW. The diagnosis and treatment of tuberculosis of the breast. Can Med Assoc J 1963;89:1118-24.

20. Singal R, Bala J, Gupta S, Goyal S, Mahajan N, Chawla A, et al. Primary breast tuberculosis presenting as a lump: A rare modern disease. Ann Med Health Sci Res 2013;3:110-2.

21. Vassilakos P. Tuberculosis of breast: Cytological findings with fine needle aspiration. Acta Cytol 1973;17:160-5.

22. Gulpinar KS, Ozis E, Ozdemir S, Korkmaz A. Primary breast tuberculosis: Report of a case. Surg Sci 2013;4:68-71.

23. Kervancioglu S, Kervancioglu R, Ozkur A, Sirikci A. Diagn Interv
Radiol 2005;4:210-2.

24. Chandanwale SS, Buch AC, Gore CR, Ramanpreet KC, Jadhav P. Fine needle aspiration cytology in breast tuberculosis: Diagnostic difficulties - Study of eleven cases. Indian J Tuberc 2012;59:162-7.

25. Tauro LF, Martis JS, George C, Kamath A, Lobo G, Hegde BR, et al. Tuberculous mastitis presenting as breast abscess. Oman Med J 2011;26:53-5.

26. Shinde SR, Chandawarkar RY, Deshmukh SP. Tuberculosis of the breast masquerading as carcinoma: A study of 100 patients. World J Surg 1995;19:379-81.

27. Kakkar S, Kapila K, Sing MK, Verma K. Tuberculosis of the breast. A cytomorphological study. Acta Cytol 2000;44:292-6.

28. Jadhav PS, Pagaro PM, Verma A, Deshpande A. Tubercular breast abscess. Med J DY Patil Univ 2013;6:206-7.

29. De Sousa R, Patil R. Breast tuberculosis or granulomatous mastitis: A diagnostic dilemma. Ann Trop Med Public Health 2011;4:122-5.

30. Mehrotra R. Fine needle aspiration diagnosis of tuberculous mastitis. Indian J Pathol Microbiol 2004;47:377-80.

31. Tewari M, Shukla HS. Breast tuberculosis: Diagnosis, clinical features and management. Indian J Med Res 2005;122:103-10.

32. Gupta PP, Gupta KB, Yadav RK, Agarwal D. Tuberculous mastitis - A review of seven consecutive cases. Indian J Tuberc 2003;50:47-50.

33. Mudduwa LK, Nagahawatte Ade S. Diagnosis of tuberculous lymphadenitis: Combining cytomorphology, microbiology and molecular techniques - A study from Sri Lanka. Indian J Pathol Microbiol 2008;51:195-7. 